Journal of Biotechnology and Strategic Health Research

\author{
Araştırma Makalesi /Research Article
}

http://dergipark.org.tr/tr/pub/bshr

\title{
Hemodializ Hastalarında COVID-19'un Klinik Seyri ve Mortalite Öngördürüicüleri, Tek Merkez Deneyimi
}

\section{Clinical Course and Mortality Predictors of COVID-19 In Hemodialysis Patients, Single Center Experience}

\section{(iD $₫$ Oğuz Evlice ${ }^{1}$, iD Damla Öz Şendoğan², iD Öznur Ak ${ }^{1}$}

${ }^{1}$ İnfeksiyon Hastalıkları ve Klinik Mikrobiyoloji, Kütahya Sağllk Bilimleri Üniversitesi, Kütahya Türkiye

${ }^{2}$ Nefroloji Kliniği, Ağrı Eğitim ve Araştırma Hastanesi, Ağrı, Türkiye

ORCID ID: Oğuz Evlice https://orcid.org/0000-0001-6939-0367, Damla Öz Şendoğan https://orcid.org/0000-0002-0167-8011,

Öznur Ak https://orcid.org/0000-0003-3790-3070

^Sorumlu Yazar / Corresponding Author: Oğuz Evlice, e-posta / e-mail: oguzevlice@hotmail.com

Geliş Tarihi / Received : 05-05-2021 Kabul Tarihi / Accepted: 21-05-2021 $\quad$ Yayın Tarihi / Online Published: 30-08-2021

Evlice O., Aydoğan D.Ö., Ak Ö. Clinical Course and Mortality Predictors of COVID-19 in Hemodialysis Patients, Single Center Experience,

J Biotechnol and Strategic Health Res. 2021;5(2):105-112

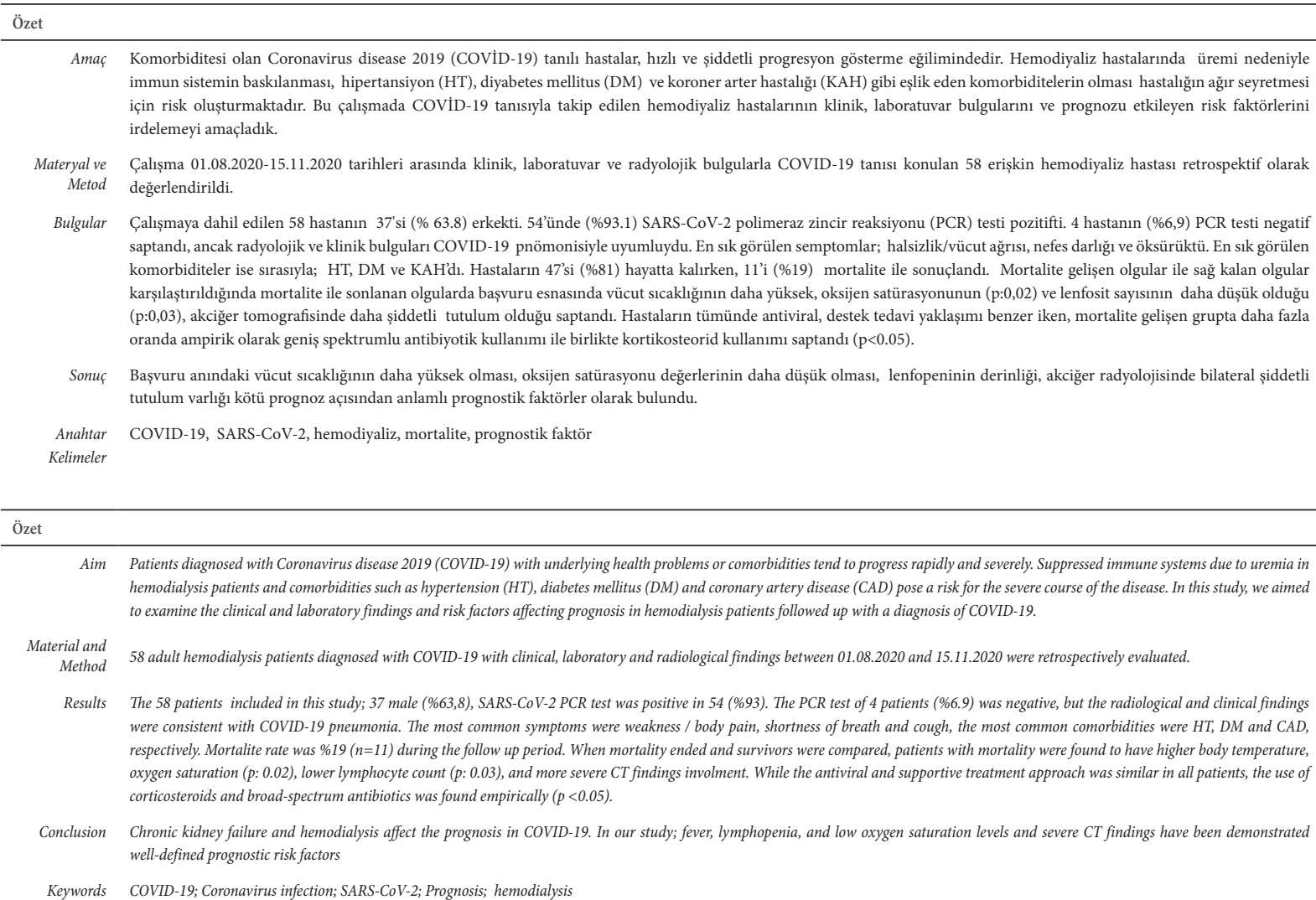

Bulgular Calıșmaya dahil edilen 58 hastanın 37'si (\% 63.8) erkekti. 54'ünde (\%93.1) SARS-CoV-2 polimeraz zincir reaksiyonu (PCR) testi pozitifti. 4 hastanın (\%6,9) PCR testi negatif saptandı, ancak radyolojik ve klinik bulguları COVID-19 pnömonisiyle uyumluydu. En sık görülen semptomlar; halsizlik/vücut ağrısı, nefes darlığı ve öksürüktü. En sık görülen komorbiditeler ise sırasıyla; HT, DM ve KAH'd. Hastaların 47'si (\%81) hayatta kalırken, 11'i (\%19) mortalite ile sonuçlandı. Mortalite gelișen olgular ile sağ kalan olgular karșılaștırıldığında mortalite ile sonlanan olgularda başvuru esnasında vücut sıcaklığının daha yüksek, oksijen satürasyonunun (p:0,02) ve lenfosit sayısının daha düşük olduğu (p:0,03), akciğer tomografisinde daha șiddetli tutulum olduğu saptandı. Hastaların tümünde antiviral, destek tedavi yaklașımı benzer iken, mortalite gelișen grupta daha fazla oranda ampirik olarak geniş spektrumlu antibiyotik kullanımı ile birlikte kortikosteorid kullanımı saptandı $(\mathrm{p}<0.05)$.

Sonuç Başvuru anındaki vücut sıcaklığının daha yüksek olması, oksijen satürasyonu değerlerinin daha düșük olması, lenfopeninin derinliği, akciğer radyolojisinde bilateral șiddetli tutulum varlığı kötü prognoz açısından anlamlı prognostik faktörler olarak bulundu.

Anahtar COVID-19, SARS-CoV-2, hemodiyaliz, mortalite, prognostik faktör

Özet

Aim Patients diagnosed with Coronavirus disease 2019 (COVID-19) with underlying health problems or comorbidities tend to progress rapidly and severely. Suppressed immune systems due to uremia in hemodialysis patients and comorbidities such as hypertension (HT), diabetes mellitus (DM) and coronary artery disease (CAD) pose a risk for the severe course of the disease. In this study, we aimed to examine the clinical and laboratory findings and risk factors affecting prognosis in hemodialysis patients followed up with a diagnosis of COVID-19.

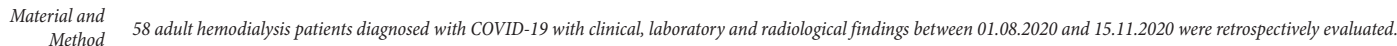

Results The 58 patients included in this study; 37 male (\%63,8), SARS-CoV-2 PCR test was positive in 54 (\%93). The PCR test of 4 patients (\%6.9) was negative, but the radiological and clinical findings were consistent with COVID-19 pneumonia. The most common symptoms were weakness / body pain, shortness of breath and cough, the most common comorbidities were HT, DM and CAD, respectively. Mortalite rate was $\% 19(n=11)$ during the follow up period. When mortality ended and survivors were compared, patients with mortality were found to have higher body temperature, oxygen saturation (p: 0.02), lower lymphocyte count (p: 0.03), and more severe CT findings involment. While the antiviral and supportive treatment approach was similar in all patients, the use of corticosteroids and broad-spectrum antibiotics was found empirically $(p<0.05)$.

Conclusion Chronic kidney failure and hemodialysis affect the prognosis in COVID-19. In our study; fever, lymphopenia, and low oxygen saturation levels and severe CT findings have been demonstrated well-defined prognostic risk factors

Keywords COVID-19; Coronavirus infection; SARS-CoV-2; Prognosis; hemodialysis 


\section{GíRiș}

COVİD-19'un klinik seyri bir hayli değişkenlik göstermekte olup asemptomatik ya da hafif klinik seyirden ağır pnömoniye ve solunum yetmezliğine kadar ilerleyebilmektedir. Şiddetli olgularda güçlü bir immun yanıtın eşlik ettiği sitokin firtınası semptomların kötüleşmesine katkı sağlamaktadır. ${ }^{1,2}$ Komorbiditesi olan COVID-19 tanılı hastalar, hızlı ve şiddetli progresyon gösterme eğilimindedir. ${ }^{1,3}$ Hemodiyaliz hastalarında üremi nedeniyle immün sistemin baskılanması, eşlik eden HT, DM ve KAH gibi komorbiditeleri hastalığın ağır seyretmesi için risk oluşturmaktadır. ${ }^{3,4}$ Bu çalışmada COVID-19 tanısıyla takip edilen hemodiyaliz hastalarının klinik, laboratuvar bulgularını ve prognozu etkileyen risk faktörlerini irdelemeyi amaçladık.

\section{MATERYAL VE METOD}

\section{Çalışma dizaynı ve katılımcılar}

Çalışmaya 01.08.2020-15.11.2020 tarihleri arasında 18 yaşından büyük COVİD-19 tanısı konulan hemodiyaliz hastaları dahil edildi. Olgu tanımları Dünya Sağlık Örgütü tanımlamalarına göre yapıldı. Hastanın solunum yolu örneğinde SARS- CoV-2 "real-time" revers transkriptaz polimeraz zincir reaksiyonu (RT-PCR) testi sonucunun pozitif olmas1, kesin olgu; hastada SARS-CoV-2 RT-PCR testi negatif olmakla birlikte, uygun klinik şikayetlerin olması ve toraks bilgisayarlı tomografisi (BT)'de COVID-19 viral pnömonisiyle uyumlu bulgular saptanması ise olası olgu olarak kabul edildi5 ${ }^{5}$. Görüntüleme yöntemlerinden toraks BT değerlendirmesinde üç veya daha az odakta hepsi 3 cm'den küçük buzlu cam dansitesi varlığ 1 hafif pnömoni; üçten fazla odakta veya 3 cm'den büyük buzlu cam dansitesi veya konsolidasyon varlığı orta pnömoni; her iki akciğerde tüm loblarda tutulum olması ve lezyonların en az üçünün 3 cm’den büyük olması ağır pnömoni olarak s1nıflandırıld ${ }^{6}$. Klinik, laboratuvar ve radyolojik bulgularla birlikte değerlendirilen hastalara hidroksiklorokin ve/veya favipravir başlandı. Başvuru anında veya takibinde oksijen saturasyonu (sPO2)<90\% olan hastalara deksametazon 6 mg veya eşdeğeri kortikosteroid başlandı. Sekonder bakteriyel infeksiyon gelişen hastalar günlük vizitlerde klinik ve labaratuvar bulguları ile değerlendirilerek gereğinde antibiyotik başlandı. Çalışma için Ağrı Eğitim ve Araştırma Hastanesi'nden 11.12.2020 tarihli ve 27 protokol numaralı yerel etik kurul onayı alındı.

\section{Verilerin Toplanması}

Hastaların demografik verileri, eşlik eden hastalıkları, laboratuvar ve akciğer tomografisi bulguları retrospektif olarak hastane bilgi sisteminden elde edildi. Hastaların kabul tarihi, taburculuk, yoğun bakıma transfer/mortalite tarihi, temas öyküsü, sigara kullanımı, başvuru sırasındaki semptomları, başvuru sırasındaki vital bulgularının yanı sıra laboratuvar tetkikleri kaydedildi. Hastaların yatışı s1rasında saptanan en yüksek ferritin ve CRP değerleriyle en düşük lenfosit sayıları da kaydedildi. Tedavide hidroksiklorokin, ve/veya favipiravir, steroid kullanımı ve koinfeksiyon/sekonder bakteriyel infeksiyon tanılariyla kullanılan antibiyotikler kaydedildi.

\section{İstatistiksel Analiz}

Çalışma kapsamında toplanan hasta verileri IBM Statistical Package for the Social Sciences (SPSS) for Windows 21.0 paket programı ile analiz edildi. Kategorik veriler için sıklık ve yüzde, sürekli veriler için medyan (Ortanca) tanımlayıcı değer olarak verildi. Gruplar arası karşılaştırılmalarda, iki grup için "Mann Whitney U-Testi" ve kategorik değişkenlerin karşılaştırılmasında "Ki-Kare Testi" kullanıldı. Sonuçlar, p değerinin 0,05 'ten küçük olduğu durumlarda istatistiksel olarak anlamlı kabul edildi.

\section{SONUÇLAR}

Çalışmaya dahil edilen 58 hastanın ortalama yaşı 59 olup $37(\% 63,8)$ 'si erkekti. Son dönem böbrek yetmezliği nedenleri sırasiyla 17 (\%31,5)'sinde DM, 15 (\%27,8)'inde HT, 7 (\%31,5)'sinde kronik glomerulonefrit, 6'sinda $(\% 11,1)$ otozomal dominant polikistik böbrek hastalığıydı (33 hasta $(\% 57,9)$ 'ü fistülden $24(\% 42,1)$ 'ü kateterden haftada üç kez diyalize giriyordu. Eşlik eden hastalıkları değerlendirildiğinde 38 (\%66,7)'inde HT 19 (\%33,9),'unda KAH 16 $(\% 28,6)$ 'sında DM ve $8(\% 14,3)$ 'inde kronik obstruktif ak- 
ciğer hastalığı/astım mevcuttu. Başvuru anındaki en sık semptomları sırasıyla nefes darlığı, halsizlik/vücut ağrısı, öksürük ve ateşti (Tablo 1). Mortalite ile sonlanan olguların başvuru anında ortalama vücut sıcaklığı $37,8^{\circ} \mathrm{C}$ olup sağ kalanlara göre (ortalama $36,6^{\circ} \mathrm{C}$ ) daha yüksek (p: 0,03), Arteriyel oksijen saturayonu mortalite grubunda sağ kalanlara göre belirgin olarak daha düşük bulundu ( Sırasıyla, sO2: 80 (80-85), sO2: 92 (85-93) ; p:0,022 ). Beyaz küre, trombosit sayısı, ve hemoglobin değerlerinde, ALT, AST, LDH, D- dimer, ferrritin seviyelerinde her iki grup arasında istatistiksel olarak anlamlı fark saptanmadı. Lenfosit sayısının mortlaite ile sonlanan olgularda, sağ kalanlardan belirgin olarak daha düşük olarak bulundu (sırasıyla; 505 (300-800), 900 (690-1500), p:0,004 ). Diğer laboratuvar tetkiklerinde her iki grupta istatistiksel olarak anlamlı bir fark saptanmadı. Aldıkları tedavi rejimlerine bakıldığında $36(\% 69,2)$ 'sının hidroksiklorokin, $48(\% 92,3)$ 'inin favipravir aldığı görüldü. Koinfeksiyon/sekonder bakteriyel infeksiyon nedeniyle 24 (\% 36,2) hastada antibiyotik kullanıldı. Kullanılan antibiyotik seçenekleri her iki grup için değerlendirildiğinde 20 (\%39,2)'sinde levofloksasin/ moksifloksasin, 8 (\%16,0)'inde seftriakson kullanınımı saptandı ve bu antibiyotikler açısından iki grup arasında istatistiksel olarak fark saptanmazken, piperasilin-tazobaktam, meropenem, vankomisin gibi antibiyotiklerin mortalite grubunda daha fazla kullanıldığı saptandı. (7/11 hasta $(\% 77,8)$, hayatta kalanlara 9/47 (\%21,4) (p:0,002). Steroid kullanımı açısından da $8(88,9 \%)$ sağ kalanlara göre $10(\% 26,3)$ mortalite grubunda anlamlı fark bulundu (p: 0,001). Hastaların radyolojik bulguları hafif, orta ve ağır olarak sınıflandırıldı. Hayatta kalan hastaların 9 $(\% 23,1)$ 'unda hafif $19(\% 48,7)$ 'unda orta $4(\% 10,3)$ 'ünde ağır tutulum saptandı. Özellikle mortalite olan olguların \%77.8'inde ağır, \%22.2 sinde orta tutulum ve ağır tutulumun mortalite grubunda belirgin olarak daha yüksek olduğu görüldü $(\mathrm{p}<0,0001)$. Hastalara COVID-19 tanısı ile yatışları sırasında rutin hemodiyaliz programlarına devam edildi (Tablo 2). Tüm hastalara antikoagülan proflaksi uyguland 1 . 
J Biotechnol and Strategic Health Res. 2021;5(2):105-112

EVLİCE, ŞENDOĞAN, AK, Hemodializ Hastarında COVID-19

\begin{tabular}{|c|c|c|c|c|}
\hline & Tüm COVID hastalar $\mathrm{N}=58$ & Sağ kalan $\mathrm{N}=47$ & Mortalite grubu $\mathrm{N}=11$ & p-değeri \\
\hline Yaş (yıl, medyan ve çeyrekler açıklığı (IQR)) & $59(51-70)$ & $61(48-70)$ & $59(53-70)$ & 0,87 \\
\hline Diyaliz Süresi (yıl, medyan ve çeyrekler açıklığı (IQR)) & $2(1-5)$ & $2,5(1-5)$ & $2(1-4)$ & 0,56 \\
\hline Erkek cinsiyet $(\mathrm{N}(\%))$ & $37 / 58(63,8)$ & $29 / 47(61,7)$ & $8 / 11(72,7)$ & 0.73 \\
\hline Yatış süresi & $8(0-10)$ & $6(0-10)$ & $8(8-17)$ & 0,12 \\
\hline Yoğun bakım yatış süresi & $8(7-13)$ & - & $8(7-13)$ & - \\
\hline Temas öyküsü(N (\%)) & $24 / 53(45,3)$ & $20 / 43(46,5)$ & $4 / 10(40,0)$ & 1,00 \\
\hline Öksürük(N (\%)) & $25 / 52(48,1)$ & $21 / 42(50,0)$ & $4 / 10(40,0)$ & 0,73 \\
\hline $\operatorname{Balgam}(\mathrm{N}(\%))$ & $7 / 52(13,5)$ & $4 / 42(9,5)$ & $3 / 10(30,0)$ & 0,12 \\
\hline Nefes Darlığı(N (\%)) & $30 / 53(56,6)$ & $21 / 42(50,0)$ & $9 / 11(81,8)$ & 0,09 \\
\hline Baş ağrısı(N (\%)) & $6 / 52(11,5)$ & $5 / 42(11,9)$ & $1 / 10(10,0)$ & 1,00 \\
\hline Halsizlik/ Vücut ağrısı(N (\%)) & $28 / 52(53,8)$ & $21 / 42(50,0)$ & $7 / 10(70,0)$ & 0,31 \\
\hline Bulantı(N (\%)) & $5 / 52(9,6)$ & $3 / 42(7,1)$ & $2 / 10(20,0)$ & 0,24 \\
\hline İshal(N (\%)) & $3 / 52(5,8)$ & $2 / 42(4,8)$ & $1 / 10(10,0)$ & 0,48 \\
\hline Koku Kaybı(N (\%)) & $1 / 52(1,9)$ & $1 / 42(2,4)$ & - & 1,00 \\
\hline Hipertansiyon(N (\%)) & $38 / 57(66,7)$ & $31 / 46(67,4)$ & $7 / 11(63,6)$ & 1,00 \\
\hline Anti-Hipertansif(N (\%)) & $38 / 55(69,1)$ & $31 / 44(70,5)$ & $7 / 11(63,6)$ & 0,72 \\
\hline Diyabet(N (\%)) & $16 / 56(28,6)$ & $12 / 45(26,7)$ & $4 / 11(36,4)$ & 0,71 \\
\hline Anti diyabetik tedavi(N (\%)) & $16 / 54(29,6)$ & $12 / 43(27,9)$ & $4 / 11(36,4)$ & 0,71 \\
\hline KOAH/ Astım öyküsü(N (\%)) & $8 / 56(14,3)$ & $7 / 45(15,6)$ & $1 / 11(9,1)$ & 1,00 \\
\hline Koroner Arter Hastalığı(N (\%)) & $19 / 56(33,9)$ & $15 / 45(33,3)$ & $4 / 11(36,4)$ & 1,00 \\
\hline Konjestif Kalp Yetmezliği(N (\%)) & $7 / 56(12,5)$ & $7 / 45(15,6)$ & - & 0,32 \\
\hline Malignite(N (\%)) & $1 / 55(1,8)$ & $1 / 44(2,3)$ & - & 1,00 \\
\hline Ek hastalık(N (\%)) & $4 / 56(7,1)$ & $4 / 45(8,9)$ & - & 0,57 \\
\hline Akut Böbrek Yetmezliği(N (\%)) & $1 / 56(1,8)$ & $1 / 45(2,2)$ & - & 1,00 \\
\hline Hidroksiklorokin(N (\%)) & $36 / 52(69,2)$ & $29 / 43(67,4)$ & $7 / 9(77,8)$ & 0,70 \\
\hline Faviprevir(N (\%)) & $48 / 52(92,3)$ & $39 / 43(90,7)$ & $9 / 9(100,0)$ & 1,00 \\
\hline Seftriakson(N (\%)) & $8 / 50(16,0)$ & $6 / 42(14,3)$ & $2 / 8(25,0)$ & 0,59 \\
\hline Levofloksasin/Moksifloksasin(N (\%)) & $20 / 51(39,2)$ & $15 / 42(35,7)$ & $5 / 9(55,6)$ & 0,29 \\
\hline Diğer antibiyotik(N (\%)) & $16 / 51(31,4)$ & $9 / 42(21,4)$ & $7 / 9(77,8)$ & 0,002 \\
\hline Prednol(N (\%)) & $18 / 47(38,3)$ & $10 / 38(26,3)$ & $8 / 9(88,9)$ & 0,001 \\
\hline $\mathrm{HBV}(\mathrm{N}(\%))$ & $3 / 57(5,3)$ & $3 / 46(6,5)$ & - & 1,00 \\
\hline $\operatorname{HCV}(\mathrm{N}(\%))$ & $2 / 57(3,5)$ & $1 / 46(2,2)$ & $1 / 11(9,1)$ & 0,35 \\
\hline Aile üyelerinde COVİD(N (\%)) & $9 / 51(17,6)$ & $7 / 41(17,1)$ & $2 / 10(20,0)$ & 1,00 \\
\hline Diyaliz türü $\mathrm{HD}(\mathrm{N}(\%))$ & $57 / 57(100,0)$ & $46 / 46(100,0)$ & $11 / 11(100,0)$ & 1,00 \\
\hline Trans öyküsü(N (\%)) & $3 / 56(5,4)$ & $2 / 45(4,4)$ & $1 / 11(9,1)$ & 0,49 \\
\hline Anjiyo(N (\%)) & & & & 1,00 \\
\hline Diyalize giriș şekli:Kateter & $24 / 57(42,1)$ & $19 / 46(41,3)$ & $5 / 11(45,5)$ & \\
\hline Diyalize giriş şekli:Fistül & $33 / 57(57,9)$ & $27 / 46(58,7)$ & $6 / 11(54,5)$ & \\
\hline Böbrek yetmezliği nedeni(N (\%)) & & & & 0,85 \\
\hline $\mathrm{DM}$ & $17 / 54(31,5)$ & $13 / 43(30,2)$ & $4 / 11(36,4)$ & \\
\hline HT & $15 / 54(27,8)$ & $12 / 43(27,9)$ & $3 / 11(27,3)$ & \\
\hline ODPKBH & $6 / 54(11,1)$ & $4 / 43(9,3)$ & $2 / 11(18,2)$ & \\
\hline Kronik Glomerulonefrit & $7 / 54(13,0)$ & $6 / 43(14,0)$ & $1 / 11(9,1)$ & \\
\hline Diğer & $9 / 54(16,7)$ & $8 / 43(18,6)$ & $1 / 11(9,1)$ & \\
\hline
\end{tabular}


J Biotechnol and Strategic Health Res. 2021;5(2):105-112

EVLİCE, ŞENDOĞAN, AK, Hemodializ Hastarında COVID-19

\begin{tabular}{|c|c|c|c|c|}
\hline & $\begin{array}{l}\text { COVİD-19 tanılı tüm } \\
\text { hastalar } \mathrm{N}=58\end{array}$ & Sağ kalan $\mathrm{N}=47$ & Mortalite $\mathrm{N}=11$ & p-değeri \\
\hline Vücut Sıcaklığı (medyan ve (IQR)) & $36,8(36,0-37,8)$ & $36,6(36,0-37,4)$ & $37,8(37,0-38,8)$ & 0,029 \\
\hline SpO2(medyan ve (IQR)) & $91(82-93)$ & $92(85-93)$ & $80(80-85)$ & 0,022 \\
\hline Sistolik Kan Basıncı (medyan ve (IQR)) & $135(123-140)$ & $135(120-135)$ & $140(130-155)$ & 0,09 \\
\hline Diyastolik Kan basıncı (medyan ve (IQR)) & $80(79-85)$ & $80(70-85)$ & $80(65-85)$ & 0,39 \\
\hline HGB (medyan ve (IQR)) & $11,1(10,1-12,4)$ & $11,8(10,1-12,4)$ & $11,0(10,1-12,3)$ & 0,47 \\
\hline PLTx103(medyan ve (IQR)) & $155(124-190)$ & $157(125-190)$ & $148,5(102-174)$ & 0,31 \\
\hline WBC (medyan ve (IQR)) & $5980(4700-7500)$ & $6070(4800-7500)$ & $4910(4000-6300)$ & 0,19 \\
\hline Nötrofil Sayısı (medyan ve (IQR)) & $4360(3300-5900)$ & $4400(3300-5900)$ & $3520(3100-5600)$ & 0,43 \\
\hline Lenfosit Sayısı (medyan ve (IQR)) & $880(600-1390)$ & $900(690-1500)$ & $505(300-800)$ & 0,004 \\
\hline BUN (medyan ve (IQR)) & $139(96-163)$ & $141(104-163)$ & $116(92-178)$ & 0,74 \\
\hline Kreatinin(medyan ve (IQR)) & $7,6(5,9-10,0)$ & $7,9(5,9-10,0)$ & $7,15(5,1-9,5)$ & 0,69 \\
\hline Glukoz(medyan ve (IQR)) & $116(84-160)$ & $116(82-169)$ & $116(90-138)$ & 0,83 \\
\hline AST (medyan ve (IQR)) & $17(11-30)$ & $17(11-30)$ & $23(11-29)$ & 0,65 \\
\hline ALT (medyan ve (IQR)) & $12(9-19)$ & $12(9-18)$ & $13(9-19)$ & 0,94 \\
\hline GGT (medyan ve (IQR)) & $33(17-50)$ & $35(25-49)$ & $17(13-334)$ & 0,75 \\
\hline LDH (medyan ve (IQR)) & $334(224-434)$ & $333(221-423)$ & $342(257-593)$ & 0,66 \\
\hline CRP (medyan ve (IQR)) & $7,1(1,3-22,1)$ & $6,2(1,1-22,1)$ & $11,6(5,1-26,1)$ & 0,37 \\
\hline Ferritin(medyan ve (IQR)) & $1025(714-1500)$ & 955 (694-1459) & $1300(1012,5-1500)$ & 0,11 \\
\hline D-Dimer(medyan ve (IQR)) & $0,89(0,60-2,2)$ & $0,8(0,6-2,25)$ & $1,49(0,5-2,15)$ & 1,00 \\
\hline Troponin(medyan ve (IQR)) & $11,0(7,3-18,2)$ & $10,55(8,0-18,2)$ & $14,2(4,4-16,0)$ & 0,81 \\
\hline $\mathrm{CT}(\mathrm{N}(\%))$ & & & & $<0,0001$ \\
\hline Yok & $7 / 48(14,6)$ & $7 / 39(17,9)$ & - & \\
\hline Hafif & $9 / 48(18,8)$ & $9 / 39(23,1)$ & - & \\
\hline Orta & $21 / 48(43,8)$ & $19 / 39(48,7)$ & $2 / 9(22,2)$ & \\
\hline Ağır & $11 / 48(22,9)$ & $4 / 39(10,3)$ & $7 / 9(77,8)$ & \\
\hline En Yüksek Ferritin(medyan ve (IQR)) & $1376(955-1500)$ & $1252(910-1500)$ & $1500(1376-1500)$ & 0,07 \\
\hline Çıkış Ferritin(medyan ve (IQR)) & $1045(805-1299)$ & $1045(805-1299)$ & - & - \\
\hline En Yüksek CRP (medyan ve (IQR)) & $18,2(5,6-71,0)$ & $14,6(5,0-71,0)$ & $23,7(12,2-117,5)$ & 0,28 \\
\hline Çıkış CRP (medyan ve (IQR)) & $6,1(1,8-20,1)$ & $6,1(1,8-20,1)$ & - & - \\
\hline En Düşük Lenfosit (medyan ve (IQR)) & $560(300-830)$ & $680(350-960)$ & $285(235-460)$ & 0,01 \\
\hline Çıkış Lenfosit (medyan ve (IQR)) & $930(610-1200)$ & $930(610-1200)$ & - & - \\
\hline
\end{tabular}




\section{TARTIŞMA}

İleri yaşla birlikte DM, HT ve KAH gibi komorbiditesi olan hastalar, COVID-19 için yüksek risk altındadırlar ${ }^{7}$. Bağışıklık sisteminin baskılanmış doğası ve eşlik eden komorbiditeler, hemodiyaliz hastalarını birçok bakteriyel ve viral infeksiyona olduğu gibi COVID-19 için de oldukça duyarlı hale getirmektedir., ${ }^{4,9}$

Hastaların eşlik eden hastalıklarına bakıldığında HT, DM ve KAH ilk üç sırada yer almaktadır. COVİD-19 tanısıyla takip edilen hemodiyaliz hastalarının değerlendirildiği üç çalışmada da en sık komorbiditeler benzer şekilde HT, DM ve KAH olarak sırlanmıştır. ${ }^{10,11,12}$ Nefes darlığı, halsizlik/vücut ağrısı, öksürük ve ateş başvuru anındaki en sık semptomlardı. COVİD-19 tanılı 3062 hastayı içeren bir metaanalizde başvuru semptomları değerlendirilmiş olup; hemodiyalize giren COVİD-19 tanılı hasta populasyonuna benzer olarak ateş, öksürük ve halsizlik en sık görülen semptomlar olarak bildirilmiştir. ${ }^{13}$ Stefan G ve ark. hemodiyaliz hastalarında en sık şikayetin halsizlik olduğunu özellikle de ciddi ve anemik olgularda daha fazla olduğunu bildirilmiştir. ${ }^{14}$ Oto ve ark. 109 olguyu değerlendirdikleri çalışmasında en sık görülen semptomlar; sunduğumuz çalışmaya benzer şekilde öksürük, ateş ve dispne olarak saptanmıştır. ${ }^{10}$ Semptomlar açısından yaşayan ve mortalite ile sonlanan olgularda değerlendirildiğinde dispne varlığı mortalite olan grupta yüksek oranda bildirilmiştir.

Üremi nedeniyle lenfosit ve granülosit fonksiyonlarında bozulma ve lenfopeni diyaliz hastalarında yaygın olarak görülebilmekle beraber, lenfopenin özellikle lenfosit sayısının 800'den düşük olması COVID-19 seyrinde diyaliz hastalarından bağımsız olarak kötü prognostik kriter olduğu olduğu birçok çalışmada gösterilmiştir., ${ }^{45} \mathrm{CO}$ VİD-19 tanısıyla takip edilen genel populasyondaki hastalara benzer şekilde, hemodiyalize giren hastalarda da lenfopeni mortalite için bir risk faktörü olarak değerlendirilmiştir. ${ }^{10,12}$ COVID-19'da prognoz göstergesi olarak değerlendirilen D-dimer yüksekliği, CRP'nin 10 kattan daha fazla artışı, ferrritin yüksekliği gibi biyobelirteçler çalışma- mızda mortalite için risk fakörü olarak bulunmamıştır.

COVID-19 tedavisinde etkinliği kanıtlanmış bir antiviral olmamakla beraber randomize kontrollü çalışma sonuçları ve bazı klinik çalışma sonuçları ile antiviral olarak favipravir, remdesivir, lopinavir/ritonavir gibi antiviralller kullanılmaktadır. Son yapılan randomize kontrollü çalışmalarda antiviral olarak favipravir ve remdesivirin etkinliği diğer tedavi seçeneklerine göre daha iyi görünmektedir. Ülkemiz rehber önerisinde de favipravir önerilmektedir. Ağır ve şiddetli pnömoni olgularında antiviral tedavi, antikoagülan proflaksi, destek tedavi yanı sıra deksametazon 6 mg veya eşdeğer steroid kullanımınının mortaliteyi azalltığ 1 gösterilmiştir. ${ }^{16,17,18}$ Başvuru anında veya takibinde oksijen saturasyonu (sPO2)<90\% olan hastalarda kortikosteroid kullanılmış olup; bu hasta grubu daha ağır klinik seyir riski olan hastaları temsil etmektedir. Bunun sonucu olarak mortalite ile sonlanan hastalarda da kortikosteroid kullanımı daha yüksek oranda saptanmıştır (p:0,01).

COVID-19 olgularında mortalite oranları çalışmalarda farklılık göstermektedir. Komorbidite varlığı ve kötü prognoz kriterleri varlığında mortalite artmaktadır. Bizim çalışmamızda COVID-19 pnömonisinin mortalite oranı \%18.9 olarak, çok merkezli 109 hastayı içeren ülkemiz çalışmasında mortalite \%12.8 olarak bulunmuştır. ${ }^{10}$ İspanya'da COVID-19 tanısıyla takip edilen 36 hemodiyaliz hastasının değerlendirildiği bir çalışmada hastalardan biri hariç hepsine hidroksiklorokin, \%75 ine de ek olarak lopinavir/ritonavir verilmiş olup mortalite oranı (30.5\%) daha yüksektir. ${ }^{12}$ Çin'de yapılan 66 hemodiyaliz hastasını içeren başka bir çalışmadaysa mortalite oranı \%27.2'dir. ${ }^{19}$ Ülkemizden yapılan 390 hemodiyaliz hastasını içeren çok merkezli bir çalışmada mortalite oranı \%16.2 iken, son dönem böbrek yetmezliği olmayan kontrol grubunda mortalite $\% 4$ olarak saptanmıştır. ${ }^{20}$ Mortalite riskinin genel populasyona göre arttığı son dönem böbrek yetmezliği olan hasta grubunun daha yakın klinik takibi önem arz etmektedir.

Hemodiyaliz hastalarında kateter infeksiyonu, üriner in- 
feksiyon gibi infeksiyonlar normal popülasyondan daha sıktır. Sunduğumuz çalışmada hastaların 27 (\%46.5)'sinde koinfeksiyon/sekonder bakteriyel infeksiyon ön tanısı ile ampirik antibiyotik tedavisi başlanmıştır. Levofloksasin, Moksifloksasin ve Seftriakson kullanımında sağ kalan ve mortalite gelişen hastalar kıyaslandığında anlamlı bir farklılık saptanmamıştır. Piperasilin/tazobaktam, meropenem ve vankomisin gibi daha geniş spektrumlu antibiyotikler ampirik olarak mortalite grubunda daha fazla kullanılmıştır (p:0.002). Yeni çalışmalarla güncellenen bir metaanalizde, COVİD-19 tanılı hastaların başvuru anında koinfeksiyon oranı \%3.5 iken sekonder bakteriyel infeksiyon oranı yaklaşık \%14.3 olarak saptanmıştır Antibiyotik kullanımıysa bu verilere kıyasla oldukça yüksektir (\%71.8). ${ }^{21}$

Sonuç olarak, hemodiyaliz uygulanan COVID-19 tanılı hastaların risk faktörleri genel populasyona benzer olmakla birlikte mortalite oranı daha yüksektir. Başvuru anındaki vücut sıcaklığının daha yüksek olması, oksijen satürasyonunun daha düşük olması, lenfopeninin derinliği, akciğer radyolojisinde bilateral şiddetli tutulum varlığı kötü prognoz açısından anlamlı prognostik faktörler olarak bulunmuştur.

\section{Çalışmanın kısıtlılıkları}

Çalışmanın retrospektif dizaynı, hasta sayısının kısıtlılı̆̆ı ve kontrol grubunun yer almaması kisitlılıklarındandır.

\section{Çıkar çatışması}

Yazarlar arasında çıkar çatışması bulunmamaktadır.

\section{Finansal Destek}

Çalışma için bir kurumdan finansal destek sağlanmamıştir. 
J Biotechnol and Strategic Health Res. 2021;5(2):105-112

Kaynaklar

1. Zhu N, Zhang D, Wang W, et al. A Novel Coronavirus from Patients with Pneumonia in China, 2019. N Engl J Med. 2020;382(8):727-733. doi:10.1056/nejmoa2001017

2. Fajgenbaum DC, June CH. Cytokine Storm. Longo DL, ed. N Engl J Med. 2020;383(23):2255-2273. doi:10.1056/NEJMra2026131

3. Sanyaolu A, Okorie C, Marinkovic A, et al. Comorbidity and its Impact on Patients with COVID-19. SN Compr Clin Med. 2020;2(8):1069-1076. doi:10.1007/s42399-020-003634

4. Vaziri N, Pahl M, Crum A, Nutrition KN-J of R, 2012 undefined. Effect of uremia on structure and function of immune system. Elsevier. Accessed December 29, 2020. https:// www.sciencedirect.com/science/article/pii/S105122761100210X

5. Organization WH. Global Surveillance for COVID-19 Caused by Human Infection with COVID-19 Virus: Interim Guidance 2 Probable Case.; 2020. Accessed December 23, 2020. https://www.who.int/emergencies/diseases/novel-coronavirus-2019/technical-

6. Rodrigues JCL, Hare SS, Edey A, et al. An update on COVID-19 for the radiologist A British society of Thoracic Imaging statement. Clin Radiol. 2020;75(5):323-325. doi:10.1016/j.crad.2020.03.003

7. Huang C, Wang Y, Li X, et al. Clinical features of patients infected with 2019 novel coronavirus in Wuhan, China. Elsevier. Accessed December 29, 2020. https://www.sciencedirect.com/science/article/pii/S0140673620301835

8. Vijayan A, of JB-CJ of the AS, 2018 undefined. $100 \%$ use of infection control procedures in hemodialysis facilities: Call to action. Am Soc Nephrol. Accessed December 29, 2020. https://cjasn.asnjournals.org/content/13/4/671?WT.MC_ID=TMD01\&utm_campaig$\mathrm{n}=$ Clin_J_Am_Soc_Nephrol_TrendMD_18utm_medium $=$ cpc\&utm_source=TrendMD

9. Wong P, Mak S, Lo K, Tong G, ... YW-A journal of, 2003 undefined. Clinical presentation and outcome of severe acute respiratory syndrome in dialysis patients. Elsevier. Accessed December 29, 2020. https://www.sciencedirect.com/science/article/pii/ S0272638603010849

10. Oto OA, Ozturk S, Turgutalp K, et al. Predicting the outcome of COVID-19 infection in kidney transplant recipients. BMC Nephrol. 2021;22(1). doi:10.1186/s12882-02102299-w

11. Valeri A, Robbins-Juarez S, ... JS-J of the, 2020 undefined. Presentation and Outcomes of Patients with ESKD and COVID-19. Am Soc Nephrol. Accessed December 29, 2020. https://jasn.asnjournals.org/content/early/2020/05/28/ASN.2020040470?utm_source=TrendMD\&utm_medium =cpc\&utm_campaign=I_Am_Soc_Nephrol_TrendMD_0\&WT. MC $I D=T M D 0$
12. Goicoechea M, Cámara L, international NM-K, 2020 undefined. COVID-19: clinical course and outcomes of 36 hemodialysis patients in Spain. Elsevier. Accessed December 29, 2020. https://www.sciencedirect.com/science/article/pii/S0085253820305093

13. Zhu J, Ji P, Pang J, et al. Clinical characteristics of 3062 COVID-19 patients: A meta-analysis. J Med Virol. 2020;92(10):1902-1914. doi:10.1002/jmv.25884

14. Stefan G, Maria Mehedinti A, Andreiana I, et al. Clinical features and outcome of maintenance hemodialysis patients with COVID-19 from a tertiary nephrology care center in Romania. Taylor Fr. 2020;43(1):49-57. doi:10.1080/0886022X.2020.1853571

15. Huang I, Pranata R. Lymphopenia in severe coronavirus disease-2019 (COVID-19): systematic review and meta-analysis. J Intensive Care. 2020;8(1):36. doi:10.1186/s40560020-00453-4

16. Bahl A, Van Baalen MN, Ortiz L, et al. Early predictors of in-hospital mortality in patients with COVID-19 in a large American cohort. Intern Emerg Med. 2020;15(8):1485-1499. doi:10.1007/s11739-020-02509-7

17. Xiong F, Tang H, Liu L, et al. Clinical characteristics of and medical interventions for COVID-19 in hemodialysis patients in Wuhan, China. J Am Soc Nephrol. 2020;31(7):13871397. doi:10.1681/ASN.2020030354

18. Dexamethasone in Hospitalized Patients with Covid-19 - Preliminary Report. N Engl J Med. Published online July 17, 2020. doi:10.1056/nejmoa2021436

19. Zou R, Chen F, Chen D, Xu C-L, Xiong F. Clinical characteristics and outcome of hemodialysis patients with COVID-19: a large cohort study in a single Chinese center. Taylor Fr. 2020;42(1):950-957. doi:10.1080/0886022X.2020.1816179

20. Ozturk S, Turgutalp K, ... MA-ND, 2020 undefined. Mortality analysis of COVID-19 infection in chronic kidney disease, haemodialysis and renal transplant patients compared with patients without kidney disease: a. academic.oup.com. Accessed May 14, 2021 https://academic.oup.com/ndt/article-abstract/35/12/2083/6020341

21. Langford B, So M, Raybardhan S, ... VL-CM, 2020 undefined. Bacterial co-infection and secondary infection in patients with COVID-19: a living rapid review and meta-analysis. Elsevier. Accessed December 29, 2020. https://www.sciencedirect.com/science/article/ pii/S1198743X20304237 